\title{
Factors influencing the uptake of voluntary HIV counseling and testing in rural Ethiopia: a cross sectional study
}

\author{
Hailay D. Teklehaimanot ${ }^{1,2^{*}}$, Awash Teklehaimanot ${ }^{1,2}$, Mekonnen Yohannes ${ }^{3}$ and Dawit Biratu ${ }^{1}$
}

\begin{abstract}
Background: Voluntary counseling and testing (VCT) has been one of the key policy responses to the HIV/AIDS epidemic in Ethiopia. However, the utilization of VCT has been low in the rural areas of the country. Understanding factors influencing the utilization of VCT provides information for the design of context based appropriate strategies that aim to improve utilization. This study examined the effects of socio-demographic and behavioral factors, and health service characteristics on the uptake of VCT among rural adults in Ethiopian.
\end{abstract}

Methods/design: This study was designed as a cross sectional study. Data from 11,919 adults (6278 women aged 15-49 years and 5641 men aged 15-59 years) residing in rural areas of Ethiopia who participated in a national health extension program evaluation were used for this study. The participants were selected from ten administrative regions using stratified multi-stage cluster sampling. Multivariate logistic regression analysis was performed accounting for factors associated with the use of VCT service.

Results: Overall, men (28\%) were relatively more likely to get tested for HIV than women (23.7 \%) through VCT. Rural men and women who were young and better educated, who perceived having small risk of HIV infection, who had comprehensive knowledge, no stigmatization attitude and discussed about HIV/AIDS with their partner, and model-family were more likely to undergone VCT. Regional state was also strongly associated with VCT utilization in both men and women. Rural women who belonged to households with higher socio-economic status, non-farming occupation, female-headed household and located near health facility, and who visited health extension workers and participated in community conversation were more likely to use VCT. Among men, agrarian lifestyle was associated with VCT use.

Conclusions: Utilization of VCT in the rural communities is low, and socio-economic, behavioral and health service factors influence its utilization. For increasing the utilization of VCT service in rural areas, there is a need to target the less educated, women, poor and farming families with a focus on improving knowledge and reducing HIV/AIDS related stigma. Strategy should include promoting partner and community conversations, accelerating model-family training, and using alternative modes of testing.

Keywords: HIV/AIDS, VCT utilization, HEP, HEWs, Model-family, Community conversation, Rural, Ethiopia

\footnotetext{
* Correspondence: hailaycnhde@ethionet.et

${ }^{1}$ Center for National Health Development in Ethiopia, Columbia University, Kebele 06, H No 447, PO Box 664 code 1250, Bole Sub City, Addis Ababa, Ethiopia

${ }^{2}$ The Earth Institute, Columbia University, 475 Riverside Drive, Suite 401, New York, NY 10025, USA

Full list of author information is available at the end of the article
} 


\section{Background}

Ethiopia, Africa's second most populous nation, is among the most affected by the HIV epidemic in SubSaharan Africa, where unprotected heterosexual contact and mother-to-child transmission are the main routes of transmission [1, 2]. HIV/AIDS, which continues to be a major development challenge for Ethiopia with an estimated adult prevalence of $1.5 \%$ in 2011, has stabilized in the past decade with heterogeneity between different geographic areas [3]. Although the HIV prevalence in rural Ethiopia was relatively low (0.9 \%) [3], small market towns are becoming hotspots bridging the urban-torural spread of HIV [4]. Moreover, the rural population with disproportionately low access to HIV/AIDS services is vulnerable to the risk of HIV infection, and the further spread of HIV to rural population is likely to increase as the communication and transport infrastructure improves [5].

Voluntary counseling and testing (VCT) has been one of the key policy responses to the HIV/AIDS epidemic, principally as a primary prevention strategy and as an entry point to other HIV/AIDS related services [6]. While undergoing VCT services, individuals learn about their sero-status and gain knowledge on avoiding risky behaviors to protect themselves and others [7-9]. VCT also serves as the basis for accessing HIV treatment and care as well as emotional support that enable individuals to cope with HIV-related anxiety and plan for their future [7-9].

Despite its strategic importance, the VCT uptake has been low in Ethiopia, as elsewhere in Africa [3, 10-13]. In 2005, the VCT uptake in Ethiopia was extremely low with only $4 \%$ of women and $6 \%$ of men ever tested for HIV [11], which increased to 38.8 and $41.1 \%$, respectively in 2011 following the rapid scale up of primary health care facilities, under the rural Health Extension Program (HEP), and increased accessibility to free antiretroviral drugs [3]. However, the VCT uptake in 2011 was lower among rural residents $(30.9 \%$ for women and $36 \%$ for men) compared to the urban residents (63.8\% of women and $58.5 \%$ of men).

It is widely accepted that the uptake of VCT is influenced by socio-demographic characteristics such as age, gender, marital status, educational attainment, socioeconomic status, and area of residence [12-17], behavioral and psychosocial factors such as high risk sexual partner, HIV/AIDS related knowledge, confidentiality, self-perceived risk, stigma and discrimination, and perceived benefits of VCT [10, 12-22], and health service delivery environment $[11,14,15,23,24]$.

Understanding the factors influencing the utilization of VCT provides information for the design of context based appropriate strategies to improve access. Nevertheless, studies undertaken to understand factors affecting
VCT utilization among rural population of Ethiopia are limited $[12,25]$. This study therefore seeks to examine the effects of socio-demographic and behavioral factors, and health service characteristics, with a focus on HEP, on the uptake of VCT among rural Ethiopian adults using a nationally representative sample.

\section{Methods}

\section{Setting}

The federal government structure of Ethiopia is composed of nine Regional States and two City Administrations (Addis Ababa and Dire-Dawa). The regions are Afar, Amhara, Benshangul-Gumuz, Oromia, Gambela, Harari, SNNP (Southern Nations and Nationalities and Peoples), Somali and Tigray. The regions are divided into woredas (districts), which are further divided into kebeles (the lowest administrative government units). Majority (83.6 \%) of the people in Ethiopia reside in rural areas with about $10 \%$ practicing pastoral and agro-pastoral livelihood. There are about 15,000 rural kebeles in the country, each with an average of 5000 inhabitants. The rural population has access to Primary Health Care Unit (PHCU), which is the lowest-tier in the healthcare delivery system comprising a cluster of five health posts and a referral health center. Over 15,000 health posts and 3000 health centers have been established to cover all rural areas in the country with PHCU. Over 38,000 high-school completed female Health Extension Workers (HEWs) who received one year training on HEP have been deployed to the health posts (at least two HEWs per health post). The candidates were recruited from their prospective villages to limit staff turnover and address gender, social and cultural factors in service provision. Volunteer community health workers (CHWs) who are trained as model family support the community level activities of HEWs.

The HEP package comprises 16 services covering family health, communicable diseases, and sanitation and hygiene programs. With the aims to develop personal and social skills, and increase health awareness that enable individuals to promote their own health, HEP focuses on promotive and preventive interventions with limited curative services. In addition to the promotive and preventive HIV/AIDS services, HEWs who are deployed in high HIV prevalent areas also provide HIV counseling and testing (HCT). The referral health centers are staffed with higher health professionals and all provide HCT services.

\section{Study design and sampling methods}

This study is part of a comprehensive HEP evaluation survey conducted in 2010 with the aim to assess the implementation process and effect of HEP on health outcomes of the rural population. The evaluation was designed as a multi-level cross-sectional study involving 
household, health worker, and health facility surveys. The data for this article came from the household survey.

The households were sampled from rural kebeles using a stratified multi-stage cluster sampling method with region as strata, and district, kebele and household as primary, secondary, and tertiary sampling units, respectively. The sampling frame comprised 679 districts with 14,723 rural kebeles from the 10 regions (including the rural areas of Dire Dawa). The sampling procedure involved selection of 71 districts and 312 kebeles through systematic-random sampling with probabilityproportional-to-size. A cross-sectional sample of 7128 households was selected from the 312 kebeles using the random-walk method used in the Expanded Program of Immunization cluster surveys. Household level data was collected using five modules: Socio-demographic (20 items), Family Health (90 items), Malaria and Tuberculosis (69 items), HIV/AIDS (57 items), and Hygiene and Sanitation (34 items), which were developed with some modification to the Ethiopian Demographic and Health Survey (EDHS) questionnaires [11]. The module on household socio-demographic characteristics was administered to the heads of 7098 households. The HIV/ AIDS module was administered to 12,060 adults (women aged $15-49$ years and men aged $15-59$ years).

\section{Consent and confidentiality of study data}

The study has received approval from the national ethics review committee of the Ethiopian Federal Ministry of Science and Technology, and the institutional review board of the Columbia University (IRB-AAAC8935). Study subjects were recruited in person by survey supervisors. The need for written informed consent was waived, and oral consent was obtained from each respondent using an approved information statement. Strict confidentiality of information and anonymity of data have been kept throughout the study. Data collection was carried out in January and February of 2010.

\section{Measurements}

For the analysis reported in this paper, we used data from 11,919 adults (6278 women and 5641 men) with matching data on socio-demographic and HIV/AIDS. The dependent variable was VCT utilization. The independent variables included socio-demographic, behavioral and programmatic factors. The socio-demographic variables were: gender, age, marital status, educational level, primary occupation of household head, region of residence, settlement type (pastoralist/agro-pastoral and agrarian), household's socioeconomic status and religion. Socio-economic status (SES) index variable was constructed for each household from a set of self-reported assets and living condition variables that reflect economic status using principal component analysis and households were grouped into five clusters using kmeans clustering in STATA/IC 12.0 [26].

The programmatic variables included walking distance to the nearest health facility $(<=10,10-30$ and $>30 \mathrm{~min})$, contact with HEWs (proactively visiting HEWs and visited by HEW at home), exposure to HIV/AIDS related information (never exposed, exposed through mass media, and exposed through community conversation), model-family and availability of volunteer CHWs in the village. HIV/AIDS related communications involving health workers, HEWs, community volunteers, community members and school were all considered as community conversation activities.

The behavioral variables included high-risk sexual partner in the past 12 months, self-perceived risk of HIV infection (four categories: no, small, moderate/great risk and don't know), belief that HIV/AIDS is fatal, belief that HIV/AIDS can be cured, HIV/AIDs knowledge index and stigma scale, and conversation with partner about HIV. Knowledge index was constructed by combining the responses to 7 sets of questions: a healthylooking person can have the HIV virus; HIV can't be transmitted by mosquito bites, supernatural means and sharing food; and HIV can be prevented through abstinence, being faithful to one uninfected partner and condom use. The scores were categorized into four groups: none (0-1), low (2-3), moderate (4) and high (5-7). The stigma index was constructed using four standard questions: willingness to care if a relative becomes ill with HIV; willingness to buy fresh vegetable from a food seller who has the HIV virus; allowing child to play with a child who has HIV virus; and keeping secret about a family member infected with HIV virus. The scores were categorized into four groups: no (0-1), low (2), moderate (3) and high (4) stigma.

\section{Statistical analysis}

Descriptive statistics were generated to characterize the study subjects. Univariate analysis was employed to independently assess the statistical association of the independent factors and the dependent variable. All sociodemographic variables were entered into a multivariate logistic model, while other variables were considered based on cut-off p-value $(<0.1)$ after testing multicollinarity between all variables. The analysis was carried out for men and women separately in STATA version 12, and survey weights were specified to account for sampling design in generating results that included odds ratios (OR) and $95 \%$ confidence intervals $(\mathrm{CI})$.

\section{Results}

Characteristics of the study population

A total of 11,919 people were included in the analysis (Table 1). The median age was 28 years for women 
Table 1 Background characteristics of study population by gender, rural Ethiopia, 2010

\begin{tabular}{|c|c|c|c|c|c|c|}
\hline \multirow{2}{*}{ Variables } & \multicolumn{2}{|l|}{ Total } & \multicolumn{2}{|c|}{ Women } & \multicolumn{2}{|l|}{ Men } \\
\hline & $\mathrm{N}$ & $\%$ & $\mathrm{~N}$ & $\%$ & $\mathrm{~N}$ & $\%$ \\
\hline \multicolumn{7}{|c|}{ Socio-demographic variables } \\
\hline Overall & 11,919 & & 6278 & 52.7 & 5641 & 47.3 \\
\hline \multicolumn{7}{|l|}{ Age group, year } \\
\hline $15-19$ & 1342 & 11.3 & 770 & 12.3 & 572 & 10.1 \\
\hline $20-24$ & 1785 & 15.0 & 1123 & 17.9 & 662 & 11.7 \\
\hline $25-29$ & 2196 & 18.4 & 1357 & 21.6 & 839 & 14.9 \\
\hline $30-39$ & 3635 & 30.5 & 1921 & 30.6 & 1714 & 30.4 \\
\hline $40+$ & 2961 & 24.8 & 1107 & 17.6 & 1854 & 32.9 \\
\hline
\end{tabular}

Marital status

\section{Married \\ Never married \\ Divorced/Widowed}

Educational level

Never attended $/<1$ year
Primary
Secondary or higher

Gender of household head

Female
Male

Occupation of household head

Farmer
Gov't employee/merchant
Other

Religion

Orthodox
Islam
Protestant
Other

Socio-economic status index

Low
Low-middle
Middle
High-middle
High

Settlement pattern

$$
\begin{aligned}
& \text { Pastoral/agro-pastoral } \\
& \text { Agrarian }
\end{aligned}
$$$$
1724
$$$$
10,195
$$$$
4749
$$$$
4122
$$$$
2527
$$$$
494
$$

4192

3586

1720

329

1724

Region

Tigray
Afar
Amhara
Oromia
Benshangul-Gumuz

9400

644

78.9

$$
4973
$$$$
758
$$

542

5.5

58.2

23.8

15.4

15.1

84.8

1233

5041

4386

1183

619

89.7

4.8

4.4

5599

314

291

39.8

2493

2170

1331

270

79.3

12.1

8.6

4427

1102

109

78.5

19.6

1.9

70.9

19.1

2548

1652

1213

47.1

10.0

19.7

80.4

561

5072

10.0

90.0

34.6

21.2

4.1

17.5

35.2

30.1

14.4

2.8

14.5

85.5

1123

2233

1863

884

170

909

5369

9.7

3.0

22.5

23.9

5.4

$\begin{array}{ll}1152 & 9.7 \\ 358 & 3.0 \\ 2677 & 22.5 \\ 2852 & 23.9 \\ 644 & 5.4\end{array}$

622

191

1409

1461

90.3

5.1

4.7

5089

91.3

255

228

4.6

4.1

39.8

2256

40.1

34.6

1952

34.7

21.3

1196

21.3

4.3

224

4.0

17.9

961

17.1

35.6

1959

34.8

29.7

1723

30.6

14.1

836

14.8

2.7

159

2.8

815

14.5

4826

85.6

85.5

9.9

530

9.4

3.0

167

3.0

22.4

1268

22.5

330

23.3

1391

24.7

5.3

314

5.6 
Table 1 Background characteristics of study population by gender, rural Ethiopia, 2010 (Continued)

\begin{tabular}{lllllll}
\hline SNNP & 2063 & 17.3 & 1052 & 16.8 & 1011 & 17.9 \\
Gambela & 1128 & 9.5 & 649 & 10.3 & 479 & 8.5 \\
Dire Dawa & 137 & 1.1 & 83 & 1.3 & 54 & 1.0 \\
Harari & 170 & 1.4 & 93 & 1.5 & 77 \\
Somali & 738 & 6.2 & 388 & 6.2 & 350
\end{tabular}

Behavioral variables

Risk partner in past 12 months

$\begin{array}{lllllll}\text { No } & 11,694 & 98.1 & 6177 & 98.4 & 5517 & 97.8 \\ \text { Yes } & 225 & 1.9 & 101 & 1.6 & 124 & 2.2\end{array}$

Self-perceived risk of HIV

No risk
Small risk
Moderate/great risk
Don't know

Believes HIV/AIDS is fatal

$$
\begin{aligned}
& \text { No } \\
& \text { Yes }
\end{aligned}
$$

7128

1183

708

2900

2113

9806

Believes HIV/AIDS can be cured

$$
\text { No }
$$

Yes

10,321

1598

HIV/AIDS knowledge index

None
Low
Moderate
High

HIV/AIDS stigma scale

No stigma
Low stigma
Moderate stigma
High stigma

Talked with partner about HIV

No
Yes

Programmatic variables

Walking distance to HF

$$
\begin{aligned}
& <=10 \mathrm{~min} \\
& 10-30 \mathrm{~min} \\
& 30+\text { minutes }
\end{aligned}
$$

4151

2592

3007

2169

4222

2049

3009

2639

6436

5483

9510

1639

770

Proactively visited HEW

No
Yes

7242

4373

6511

5016

HEW visited home

No
Yes

es

511

59.8
9.9
5.9
24.3

3581

573

360

1764

17.7

1336

4942

21.3

78.7

57.0

3547

610

348

1136

82.3

86.6

5458

820

86.9

13.1

777

4864

13.8

13.4

34.8

2597

1328

41.4

21.2

23.2

1455

14.3

18.2

898

$$
35.4
$$

1907

1020

1671

25.2

22.1

1680

54.0

46.0

3668

2610

41.6

2768

2873

49.1

50.9

$\begin{array}{ll}79.8 & 5016 \\ 13.8 & 861\end{array}$

79.9

4494

79.7

6.5

401

13.7

778

13.8

6.4

369

6.5

60.8

3839

62.5

3403

62.2

36.7

2304

37.5

2069

37.8

$54.6 \quad 3474$

57.0

3037

55.9

42.1

2624

43.0

2392

44.1 
Table 1 Background characteristics of study population by gender, rural Ethiopia, 2010 (Continued)

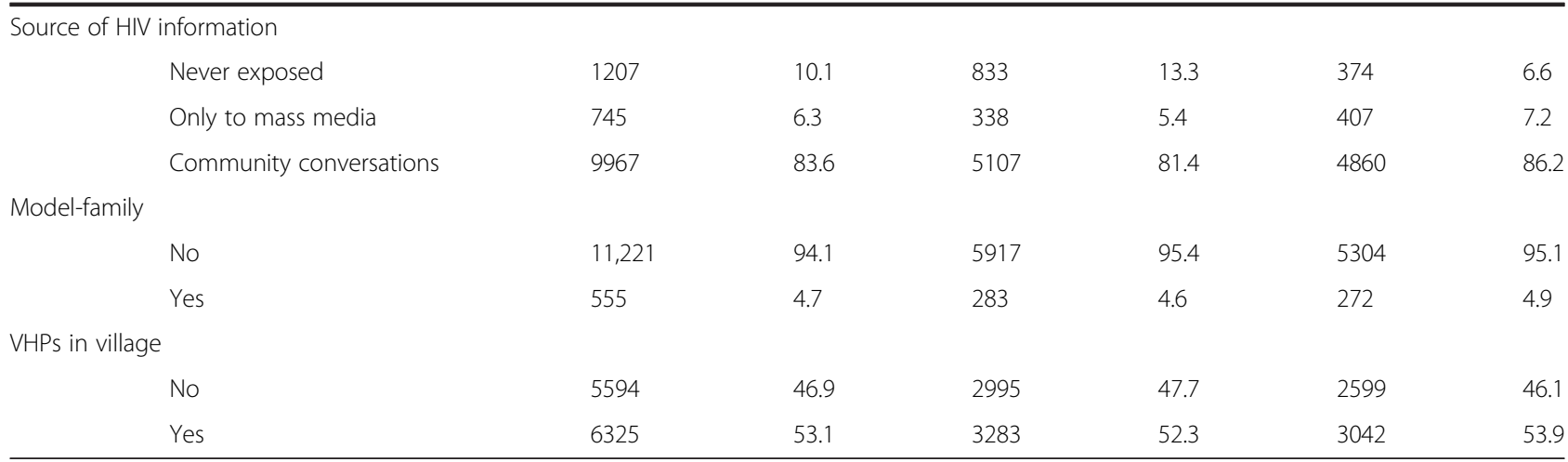

(52.7\%) and 33 years for men (47.3\%). Majority of respondents came from male-headed (85\%) and farming households (90\%). Majority (78.9\%) were married and about $58 \%$ (70.9 \% of women and $47.1 \%$ of men) had never attended or completed one year of formal education. About $14.5 \%$ of respondents were from pastoral or agro-pastoral communities.

About $2 \%$ of respondents reported high-risk sexual partner in the 12 months prior to the survey, and majority $(59.8 \%)$ perceived no risk of HIV infection, while only $5.9 \%$ perceived moderate or great risk. Only $18.2 \%$ ( $14.3 \%$ of women and $22.5 \%$ of men) had comprehensive knowledge about HIV/AIDS. While 35.4\% (30.4\% of women and $41 \%$ of men) had no stigma towards people living with HIV, about $22 \%$ (26.8 \% of women and $17 \%$ of men) had high levels of stigma.

About $80 \%$ of respondents reside within 10 min walking distance to health facility. About $37 \%$ proactively visited HEWs during the month prior to the survey. Majority (83.6 \%) was exposed to HIV/AIDS related information through community conversations. Overall, $25.8 \%$ (23.7 \% for women and $28 \%$ for men) had been tested for HIV. Over half (53.1\%) of respondents were from villages with active CHWs, and only $4.7 \%$ were from model-family households.

\section{Univariate logistic regression}

The result of univariate logistic regression analysis by gender is presented in Table 2. Socio-demographic factors significantly associated with VCT uptake among both women and men were: age and educational attainment, occupation of household head, wealth index, agroecological zone, and region. The results showed that self-perceived risk of HIV, belief on whether HIV/AIDS is fatal, and conversation with partner about HIV/AIDS were significantly associated with VCT uptake in both men and women. VCT uptake increased significantly with increased levels of HIV/AIDS related knowledge index, while it decreased significantly with increasing stigma scale. Risky sexual partner in the past 12 months was significantly associated with VCT uptake only among women. Contact with HEWs, sources of HIV information, model-family, and $\mathrm{CHWs}$ were significantly associated with the use of VCT in both genders. However, proximity to a health facility was only significantly associated with VCT uptake among women.

\section{Multivariate logistic regression Women}

The result of multivariable logistic regression by gender is presented in Table 2. Socio-demographic factors independently associated with increased VCT uptake among women were: $20-24$ years age group $(\mathrm{OR}=1.4 ; 95 \% \mathrm{CI}$ 1.1-1.9); attainment of primary $(\mathrm{OR}=1.7 ; 95 \% \mathrm{CI} 1.3-$ 2.3) and secondary/higher $(\mathrm{OR}=1.7$; $95 \%$ CI 1.2-2.3) education; household head being merchant or government employee $(\mathrm{OR}=1.7 ; 95 \% \mathrm{CI} 1.2-2.8)$; Islam religion $(\mathrm{OR}=1.8 ; 95 \% \mathrm{CI} 1.2-2.8)$; and wealth index middle-high $(\mathrm{OR}=1.4 ; 95 \% \mathrm{CI}$ 1.03-2.0) and high $(\mathrm{OR}=1.9 ; \quad 95 \%$ CI 1.1-3.1); while male-headed household was associated with decreased uptake of VCT $(\mathrm{OR}=0.5 ; 95 \%$ CI 0.4-0.7). Women's marital status and agro-ecological settlement were not significantly associated with VCT uptake.

Women who perceived themselves to be at small risk of HIV were 2.3 times more likely to receive VCT in comparison with those who perceived to have no risk. The odds of VCT uptake among women with comprehensive HIV/AIDS knowledge were 2.3 (95 \% CI 1.453.72) times higher than those who lacked any HIV/AIDS related knowledge. The uptake of VCT was higher among women who talked about HIV with their partner $(\mathrm{OR}=2.27 ; 95 \% \mathrm{CI} 1.86-2.77)$. The uptake of VCT among women with high levels of stigma was significantly lower $(\mathrm{OR}=0.65 ; 95 \% \mathrm{CI} 0.46-0.93)$ in comparison with those who showed positive attitude.

Women who walk for more than $30 \mathrm{~min}$ to reach the nearest health facility were less likely $(\mathrm{OR}=0.60 ; 95 \% \mathrm{CI}$ 
Table 2 Result of logistic regression of the association between VCT uptake and explanatory factors by gender, rural Ethiopia 2010

\begin{tabular}{|c|c|c|c|c|c|c|c|c|}
\hline \multirow{3}{*}{ Variables } & \multicolumn{4}{|c|}{ Women } & \multicolumn{4}{|c|}{ Men } \\
\hline & \multicolumn{2}{|c|}{ Unadjusted } & \multicolumn{2}{|c|}{ Adjusted } & \multicolumn{2}{|c|}{ Unadjusted } & \multicolumn{2}{|c|}{ Adjusted } \\
\hline & OR & $95 \% \mathrm{Cl}$ & OR & $95 \% \mathrm{Cl}$ & OR & $95 \% \mathrm{Cl}$ & OR & $95 \% \mathrm{Cl}$ \\
\hline
\end{tabular}

Socio-demographic variables

Age group, year

20-24

25-29

30-39

$40+$

Marital status

Married
Never married
Divorced/Widowed

Divorced/Widowed

Educational level

Never attended $/<1$ year

Primary

Secondary and higher

1.43

1.07

0.85

0.56

$1.13-1.80$
$0.80-1.44$
$0.65-1.11$
$0.42-0.73$

1

1.43

1.13

0.85

0.66

$1.06-1.92$

0.73-1.76

$0.57-1.27$

$0.45-0.96$

1

0.69

1.3

$0.99-1.71$

$1.01-1.90$

1.11

$0.47-1.02$

$0.71-1.75$

1.38

\section{1}

2.41

3.1

1.90-3.06

$2.28-4.20$

1

1.71

1.66

$1.29-2.26$

$1.21-2.28$

1

$0.62-1.30$

0.53

$0.39-0.73$

0.9

Male

Occupation of household head

Farmer

Gov't employee/merchant

Other

\section{1}

2.58

1.02

$1.79-3.70$

$0.60-1.72$

Religion

Orthodox

Islam

Protestant

Other

Socio-economic status index

Low
Low-middle
Middle
High-middle
High

Settlement pattern

Pastoral

Agrarian

Region

Tigray
Afar
Amhara
Oromia
Benshangul-Gumuz

\section{1}

0.88

1.21

0.9

0.54-1.43

$0.77-1.89$

$0.48-1.67$

\section{1}

1.65

1.29

$1.13-2.41$

$0.64-2.59$

1

1.84

0.98

$1.22-2.78$

$0.61-1.57$

1.37

$0.64-2.94$

\section{1}

1.44

2.01

2.46

4.48

1.04-2.00

1.35-3.00

1.63-3.74

2.53-7.94

1

2.02

1.04-3.90

1

0.35

0.42

0.26

0.31

$0.18-0.67$

$0.22-0.82$

$0.14-0.47$

$0.12-0.82$

\section{1}

1.24

1.30

0.94-1.64

0.93-1.80

$$
1.43
$$

1.03-1.98

1.86

1.12-3.09

\section{1}

1.4

$0.78-2.50$

\section{1}

0.38

0.69

0.14-1.00

0.34

$0.41-1.16$

0.16-0.74

0.53

$0.21-1.33$
1

1.93
1.99
1.51
1.09

1.93
1.99

$\begin{array}{ll}1.51-2.47 & 1.68 \\ 1.50-2.63 & 1.84 \\ 1.16-1.96 & 1.33 \\ 0.82-1.46 & 1.08\end{array}$

$1.19-2.37$

$1.26-2.68$

0.86-2.06

$0.67-1.72$ 
Table 2 Result of logistic regression of the association between VCT uptake and explanatory factors by gender, rural Ethiopia 2010 (Continued)

$\begin{array}{lllllllll}\text { SNNP } & 0.57 & 0.31-1.06 & 0.74 & 0.36-1.53 & 0.78 & 0.45-1.35 & 0.73 & 0.37-1.47 \\ \text { Gambela } & 0.19 & 0.09-0.36 & 0.36 & 0.16-0.83 & 0.18 & 0.09-0.38 & 0.21 & 0.08-0.54 \\ \text { Dire Dawa } & 0.75 & 0.17-3.26 & 1.81 & 0.46-7.10 & 0.67 & 0.41-1.11 & 1.92 & 0.82-4.52 \\ \text { Harari } & 0.19 & 0.11-0.35 & 0.50 & 0.23-1.10 & 0.14 & 0.09-0.24 & 0.2 & 0.1-0.42 \\ \text { Somali } & 0.02 & 0.01-0.07 & 0.03 & 0.01-0.11 & 0.03 & 0.01-0.08 & 0.08 & 0.03-0.21\end{array}$

Behavioral variables

Risk partner in past 12 months

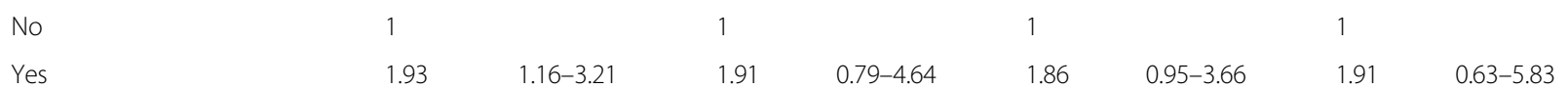

Self perceived risk of HIV

No risk
Small risk
Moderate/great risk
Don't know

Believes HIV/AIDS is fatal

$$
\text { No }
$$

Yes

Believes HIV/AIDS can be cured

$$
\begin{aligned}
& \text { No } \\
& \text { Yes }
\end{aligned}
$$

HIV/AIDS knowledge index

None
Low
Moderate
Comprehensive knowledge

HIV/AIDS stigma scale

$$
\begin{aligned}
& \text { No stigma } \\
& \text { Low stigma } \\
& \text { Moderate stigma } \\
& \text { High stigma }
\end{aligned}
$$

Talked with partner about HIV

$$
\begin{aligned}
& \text { No } \\
& \text { Yes }
\end{aligned}
$$

Programmatic variables

Walking distance to HF

$$
\begin{aligned}
& <=10 \mathrm{~min} \\
& 10-30 \mathrm{~min} \\
& 30+\text { minutes }
\end{aligned}
$$

Proactively visited HEW

$$
\begin{aligned}
& \text { No } \\
& \text { Yes }
\end{aligned}
$$

HEW visited home

$$
\text { No }
$$$$
\text { Yes }
$$

\section{1}

1.99

$0.17-0.36$

3.71

$2.58-5.34$

0.88

$0.61-1.28$

1.35-4.07

$0.60-1.51$

$0.50-1.09$

1

1.46

0.94-2.25

1

1.01

$0.59-1.74$

0.19-0.40

0.27

1.15-3.02

0.86-1.84

.

\section{1}

1.25

$0.91-1.73$

\section{1}

3.52

$2.50-5.00$

1

1.27

0.89-1.82 
Table 2 Result of logistic regression of the association between VCT uptake and explanatory factors by gender, rural Ethiopia 2010 (Continued)

\begin{tabular}{|c|c|c|c|c|c|c|c|c|}
\hline \multicolumn{9}{|l|}{ Exposure to HIV information } \\
\hline Never exposed & 1 & & 1 & & 1 & & 1 & \\
\hline Only to mass media & 8.31 & $3.34-20.71$ & 5.42 & $1.89-15.54$ & 6.07 & $2.08-17.76$ & 1.91 & $0.69-5.29$ \\
\hline Community conversations & 19.68 & $8.61-45-02$ & 5.92 & $2.38-14.72$ & 12 & $4.55-31.59$ & 2.52 & $0.96-6.65$ \\
\hline \multicolumn{9}{|c|}{ Household graduated as model-family } \\
\hline No & 1 & & 1 & & 1 & & 1 & \\
\hline Yes & 3.06 & $2.09-4.48$ & 1.50 & $1.03-2.18$ & 4.34 & $2.81-6.70$ & 2.65 & $1.72-4.07$ \\
\hline \multicolumn{9}{|l|}{ VHPs in village } \\
\hline No & 1 & & 1 & & 1 & & 1 & \\
\hline Yes & 3.12 & $2.14-4.54$ & 1.44 & $1.00-2.06$ & 2.91 & $2.02-4.19$ & 1.37 & $0.98-1.90$ \\
\hline
\end{tabular}

$0.42-0.87)$ to receive VCT in comparison with those who reside within 10 min walking distance. The odds of VCT uptake among women who proactively visit HEWs were 1.40 (95\% CI 1.13-1.73) times higher than among those women who did not visit HEWs. The uptake of VCT was higher among women who received HIV information through community conversations $(\mathrm{OR}=5.92 ; 95 \% \mathrm{CI}$ 2.38-14.72) in comparison with those who were not exposed to any HIV related information. The odds of VCT uptake among women from model-family were 1.50 (95\% CI 1.03-2.18) times higher than among those from non-model family. Likewise, the odds of VCT uptake among women from villages with active $\mathrm{CHWs}$ were 1.44 (95\% CI 1.00-2.06) times higher than among those from villages without $\mathrm{CHWs}$.

\section{Men}

Socio-demographic factors independently associated with increased VCT uptake among men were: 20-29 years age group $(20-24$ years: $\mathrm{OR}=1.7 ; 95 \% \mathrm{CI} 1.2-2.4$ and 25-29 years: $\mathrm{OR}=1.8 ; 95 \%$ CI 1.3-2.7); attainment of primary $(\mathrm{OR}=1.7 ; 95 \% \mathrm{CI} 1.4-2.1)$ and secondary/ higher $(\mathrm{OR}=2.4 ; 95 \% \mathrm{CI} 1.8-3.1)$ education; Islam religion $(\mathrm{OR}=1.6$; $95 \% \mathrm{CI} 1.1-2.3)$; and agrarian (settled) dwellers $(\mathrm{OR}=1.9 ; 95 \% \mathrm{CI}$ 1.2-3.2). Marital status, household head's gender, occupation and wealth index were not significantly associated with VCT uptake among men respondents.

Men who perceived themselves to be at small risk of HIV were 1.86 (95 \% CI 1.15-3.02) times more likely to receive $\mathrm{VCT}$ in comparison with those who perceived to have no risk; while men who could not state their perceived risk of HIV were less likely be tested $(\mathrm{OR}=0.62$; $95 \%$ CI 0.42-0.90) compared to those with no risk. The odds of VCT uptake among men with comprehensive HIV/AIDS knowledge were 1.96 (95 \% CI 1.23-3.13) times higher than among those men who lacked any HIV/AIDS related knowledge. The uptake of VCT was higher among men who talked with their partner about HIV (OR = 2.09; 95 \% CI 1.61-2.71). The uptake of VCT among men with high levels of stigma towards people living with $\mathrm{HIV}$ was significantly lower $(\mathrm{OR}=0.56$; $95 \%$ CI 0.38-0.80) in comparison with those who showed positive attitude.

The odds of VCT uptake among men from modelfamily were 2.65 (95\% CI 1.72-4.07) times higher than among their counter parts. All other programmatic variables included in this study were not significant predicators of VCT uptake among men.

\section{Discussion}

While the utilization of VCT improved considerably compared to 2005 levels, which is likely due to the increased number of health facilities providing HCT services, introduction of lay counselors and providerinitiated testing initiatives, and increased accessibility to free anti-retroviral drugs $[3,11]$, the uptake in rural areas was low in comparison with the urban areas [3]. This study examined the association between sociodemographic, behavioral and health service factors and VCT uptake in rural Ethiopia using a nationally representative cross sectional sample of adults. The findings in this study has shown that several socio-demographic, behavioral and health service related factors were associated with HIV testing among rural men and women.

The findings showed that the proportions ever tested were significantly higher among youth, which is somehow encouraging as youth are at particularly higher risk of HIV acquisition. Our findings agree with studies conducted in Ethiopia [3], and elsewhere in Africa [14, 19, 27].

Consistent with the national level EDHS data and other studies, the results show better-educated individuals are more likely to be tested for $\operatorname{HIV}[3,16,19,28,29]$. Women from households with greater economic wealth were more likely to be tested for HIV consistent with 
other studies [3, 11]. Education and wealth are positively related to certain risk factors such as premarital sex [30], and associated with higher HIV prevalence [3]. Related with the effect of socio-economic status, women belonging to households whose primary occupation was trade and government job were more likely to use VCT [31].

The results showed significant difference in the uptake of VCT by region, which partly reflect the multicultural characteristics of the country and difference in the pace of implementation of the HEP. The percentage that has ever been tested for HIV ranged from about $2 \%$ in Somali to nearly $50 \%$ in Tigray. The lowest percentages of HIV testing were observed in regions with predominantly pastoral lifestyle, consistent with the overall poor health indicators reported for these regions [32]. The lower uptake of VCT in Gambella is critical as Gambela is one of the regions with the highest level of HIV prevalence $(6.5 \%)$ in the country [3]. The remote and harsh climatic condition and the highly mobile and geographically dispersed settlement coupled with poor infrastructure and social services could have contributed to the observed low uptake of VCT. However, the findings of our study suggest that agro-ecological zone had varied influence on VCT uptake in men and women. While belonging to an agrarian community was a strong predictor of VCT uptake among men, the association was non-significant among women. The overall low uptake of VCT among women regardless of agro-ecological zone suggests that all rural women face similar sociocultural barriers on VCT utilization [20]. Respondents belonging to Muslim religion were more likely to be tested, which is in contrast to other studies that reported either lack of association [33], or the opposite findings [12].

With regard to behavioral factors, VCT uptake increased sharply with increased HIV/AIDS related knowledge, which is consistent with other studies [16, 34]. The observed strong inverse association between stigma and VCT uptake is consistent with other studies, and in light of the high levels of stigma, the findings suggest that fear of stigma and discrimination is an important barrier to HIV testing [10, 12, 13, 19, 35]. The result showed that respondents with a small-perceived risk of HIV were more likely to use VCT compared to those with no-perceived risk of HIV. The low uptake of VCT among those who perceived no risk of infection, which could be due to lack of motivation to undergo HIV testing, has negative effect on the overall VCT uptake as this perception was common (60\%). In contrast to rural Tanzania [17], but consistent with findings from rural Uganda and Southern African countries [36-38], there was no evidence to suggest that a high-perceived risk of HIV was independently associated with VCT uptake. A study among youth in Ethiopia reported high-perceived risk of infection was associated with low VCT uptake [39], which could be due to fear of discrimination, in light of the prevalent stigma [22]. Individuals who talked with their partners about HIV/AIDS were more likely to use VCT, likely due to its positive effect on stigma and discrimination.

While all the programmatic factors affected VCT uptake among women, model-family was the only factor that affected VCT uptake among men. Women who resided further away from health facility were less likely to undergone VCT, likely due to household responsibilities limiting their time to travel long distance to seek health services. Women who were exposed to HIV-related information through community conversation were 5.9 times more likely to use VCT in comparison with women who were never exposed to such information. It has been reported that exposure to community conversation, particularly when individuals who were tested speak openly about HIV, led to greater acceptance and uptake of testing [37, 40, 41], which could be due to peer pressure [42]. The observed influence of volunteer CHWs and contact with HEWs in the uptake of VCT among women may be related to increased frequency of conversation about HIV. With regards to contact with HEWs, while proactive contact was associated with HIV testing, being visited at home by HEWs did not have noteworthy effect on HIV testing, which suggests that motivation play an important role, over and above the mere exposure to health information, in influencing HIV testing behaviors. On the other hand, the lack of influence of community conversation, CHWs and contact with HEWs on VCT uptake among men, and the strong influence of model-family on VCT uptake among men suggests that it takes intensive effort to bring about meaningful behavioral change among men. To graduate as a model-family, households undergo intensive theoretical and practical training on the various HEP services including HIV/AIDS for about $96 \mathrm{~h}$, and are required to implement and adopt the HEP package [4].

In the present study, men were relatively more likely to get tested than women, which is consistent with EDHS data [3], and other studies from rural Uganda [43], South Africa [44], and Zimbabwe [16]. Socioeconomic status and distance to health facility, which are important barriers to VCT use among women, could have contributed to the lower uptake among women [38]. Moreover, gender inequality and socio-cultural barriers could affect VCT demand among women [20]. In Ethiopia, fear of abandonment and divorce following discovery of HIV positive status were some of the barriers reported by women for freely seeking VCT services [22]. Although not all studies confirm gender differences in general attitudes toward testing [19]; women's decisions 
about testing could be affected by their childbearing and breastfeeding plans, and their husband's opinion [45-47]. Our finding, on the other hand, contrast with reports of higher testing rates among women from a number of other studies [25, 31, 37, 48-50], which could be due to more frequent interaction with health services during antenatal care and prevention of mother to child transmission programs $[40,41]$. However, the observed disparity could be largely due to differences in the study design and study population (rural vs urban; national vs localized samples).

\section{Limitations}

The study has some limitations. Due to the crosssectional design of the current study, causal inferences cannot be drawn from the associations. Since data was collected in face-to- face interviews, information bias might occur due to recall, sensitivity of questions, and social desirability factors. Information bias could have contributed to the low percentage $(<2 \%)$ of respondents who reported high-risk sexual behavior, which might have resulted in the lack of an association with HIV testing. Similarly, HIV testing status may be subjected to information bias. To minimize such bias, interviewers were trained to ask questions in a non-judgmental way, and respondents were assured that personal information would be confidential and de-identifiable. Moreover, engagement in high-risk sexual practice and undergoing HIV testing are easily remembered, and thus recall bias may not be a major challenge. Despite these limitations, the use of a large representative population-based sample allowing for greater generalizability and the examination of a wide range of explanatory factors were the main strengths of the current study.

\section{Conclusion}

Findings from the current study have important implications for developing intervention programs targeting rural areas in Ethiopia. First, the findings highlight individual- and community-level characteristics that influence the utilization of HIV testing, and the need for more intense efforts targeting the less educated, poor and farming families [51]. Second, the variation across regions and agro-ecological zones requires targeted capacity building and adopting appropriate delivery modalities such as mobile VCT services for pastoral regions. Third, promoting partner and community conversation, which has been the core government intervention in the national HIV/AIDS strategy [4], and speeding the scaleup of the model-family implementation should be given utmost priority to address the HIV related low knowledge and prevalent stigma. The recently introduced women development army network, which links five households to one model family, will be an important platform for effective community conversation and peer education [4]. Finally, making VCT a routine service in all health posts and provision of home-based VCT as well as provider initiated modes of testing would address the physical access barrier to rural women, while also tackling demand side barriers such as stigma and confidentiality [51-53].

\section{Availability of data and materials}

The dataset supporting the conclusions of this article is available in the Open Science Framework repository (https://osf.io/7hqz8/files/).

\section{Abbreviations}

CHWs: community health workers; EDHS: Ethiopian Demographic and Health Survey; HCT: HIV counseling and testing; HEP: health extension program; HEW: health extension worker; HIV/AIDS: Human Immunodeficiency Virus/ Acquired Immunodeficiency Disease Syndrome; PHCU: Primary Health Care Unit; PMTCT: prevention of mother to child transmission; SES: socio-economic status; SNNP: Southern Nations and Nationalities and People; VCT: voluntary counseling and testing.

\section{Competing interests}

We declare that there are no competing interests.

\section{Authors' contributions}

HT and AT conceived and designed the study methodology. HT and MY drafted the manuscript. DB and HT participated in data management and analysis. All authors participated in revising the manuscript. All authors read and approved the final manuscript.

\section{Acknowledgements}

The authors gratefully acknowledge the financial support from Blaustein Foundation, and UNICEF and WHO Ethiopia country offices. The authors would like to thank the survey coordinators, field workers, and study participants. The authors wish to thank the Federal Ministry of Health for allowing its staff to participate in the study.

\section{Author details}

${ }^{1}$ Center for National Health Development in Ethiopia, Columbia University, Kebele 06, H No 447, PO Box 664 code 1250, Bole Sub City, Addis Ababa, Ethiopia. ${ }^{2}$ The Earth Institute, Columbia University, 475 Riverside Drive, Suite 401, New York, NY 10025, USA. ${ }^{3}$ College of Health Sciences, Mekelle University, PO Box 1871, Mekelle, Ethiopia.

Received: 20 August 2015 Accepted: 1 March 2016

Published online: 08 March 2016

\section{References}

1. FMOH. Single Point HIV Prevalence Estimate. Addis Ababa: Ministry of Health and Federal HIV/AIDS Prevention and Control Office; 2007.

2. $\mathrm{FMOH}$. Report on progress towards implementation of the UN Declaration of Commitment on HIV/AIDS 2010. Addis Ababa: Federal Democratic Republic of Ethiopia, Federal HIV/AIDS Prevention and Control Office; 2010.

3. CSA. Ethiopia Demographic and Health Survey (EDHS) 2011. Calverton: Central Statistical Authority, Addis Ababa and ORC Macro; 2012.

4. FMOH. Strategic Plan II for Intensifying Multisectoral HIV and AIDS Response in Ethiopia: 2010/11-2014/15. Federal HIV/AIDS Prevention and Control Office, Federal Ministry of Health: Addis Ababa; 2010.

5. Shabbir I, Larson CP. Urban to rural routes of HIV infection spread in Ethiopia. J Trop Med Hyg. 1995;98(5):338-42.

6. Denison JA, O'Reilly KR, Schmid GP, Kennedy CE, Sweat MD. HIV voluntary counseling and testing and behavioral risk reduction in developing countries: a meta-analysis, 1990-2005. AIDS Behav. 2008;12(3):363-73.

7. $\mathrm{FMOH}$. AIDS in Ethiopia, sixth report. Federal Ministry of Health National HIV/AIDS Prevention and Control Office: Addis Ababa; 2006. 
8. UNAIDS. Voluntary counselling and testing(VCT). Geneva: UNAIDS Technical Update; 2000.

9. World Health Organization. Increasing access to HIV testing and counselling: report of a WHO consultation, 19-21 November 2002. Geneva: WHO; 2003.

10. Bwambale FM, Ssali SN, Byaruhanga S, Kalyango JN, Karamagi CA. Voluntary HIV counselling and testing among men in rural western Uganda: implications for HIV prevention. BMC Public Health. 2008;8:263.

11. CSA. Ethiopia Demographic and Health Survey (EDHS) 2005. Calverton: Central Statistical Authority, Addis Ababa and ORC Macro; 2006.

12. Leta TH, Sandoy IF, Fylkesnes K. Factors affecting voluntary HIV counselling and testing among men in Ethiopia: a cross-sectional survey. BMC Public Health. 2012;12:438,

13. Matovu JK, Makumbi FE. Expanding access to voluntary HIV counselling and testing in sub-Saharan Africa: alternative approaches for improving uptake, 2001-2007. Tropical Med Int Health. 2007;12(11):1315-22.

14. Hutchinson PL, Mahlalela X. Utilization of voluntary counseling and testing services in the Eastern Cape, South Africa. AIDS Care. 2006;18(5):446-55.

15. Obermeyer $\mathrm{CM}$, Osborn $\mathrm{M}$. The utilization of testing and counseling for HIV: a review of the social and behavioral evidence. Am J Public Health. 2007;97(10):1762-74.

16. Sherr L, Lopman B, Kakowa M, Dube S, Chawira G, Nyamukapa C, Oberzaucher N, Cremin I, Gregson S. Voluntary counselling and testing: uptake, impact on sexual behaviour, and HIV incidence in a rural Zimbabwean cohort. AIDS. 2007;21(7):851-60.

17. Wringe A, Isingo R, Urassa M, Maiseli G, Manyalla R, Changalucha J, Mngara J, Kalluvya S, Zaba B. Uptake of HIV voluntary counselling and testing services in rural Tanzania: implications for effective HIV prevention and equitable access to treatment. Tropical Med Int Health. 2008;13(3):319-27.

18. deGraft-Johnson J, Paz-Soldan V, Kasote A, Tsui A. HIV voluntary counseling and testing service preferences in a rural Malawi population. AIDS Behav. 2005;9(4):475-84.

19. Fylkesnes K, Siziya S. A randomized trial on acceptability of voluntary HIV counselling and testing. Tropical Med Int Health. 2004;9(5):566-72.

20. Maman S, Mbwambo J, Hogan NM, Kilonzo GP, Sweat M. Women's barriers to HIV-1 testing and disclosure: challenges for HIV-1 voluntary counselling and testing. AIDS Care. 2001;13(5):595-603.

21. Pool R, Nyanzi S, Whitworth JA. Attitudes to voluntary counselling and testing for HIV among pregnant women in rural south-west Uganda. AIDS Care. 2001;13(5):605-15.

22. Reilley B, Hiwot ZG, Mesure J. Acceptability and utilisation of services for voluntary counselling [corrected] and testing and sexually transmitted infections in Kahsey Abera Hospital, Humera, Tigray, Ethiopia. Ethiop Med J. 2004;42(3):173-7.

23. Jereni BH, Muula AS. Availability of supplies and motivations for accessing voluntary HIV counseling and testing services in Blantyre, Malawi. BMC Health Serv Res. 2008;8:17.

24. Mugisha E, van Rensburg GH, Potgieter E. Strategic framework for increasing accessibility and utilization of voluntary counseling and testing services in Uganda. AIDS Res Treat. 2011;2011:912650

25. Molla M, Emmelin M, Berhane Y, Lindtjorn B. Readiness of youth in rural Ethiopia to seek health services for sexually transmitted infections. Afr J AIDS Res. 2009;8(2):135-46.

26. Houweling TA, Kunst AE, Mackenbach JP. Measuring health inequality among children in developing countries: does the choice of the indicator of economic status matter? Int J Equity Health. 2003;2(1):8.

27. Baiden F, Akanlu G, Hodgson A, Akweongo P, Debpuur C, Binka F. Using lay counsellors to promote community-based voluntary counselling and HIV testing in rural northern Ghana: a baseline survey on community acceptance and stigma. J Biosoc Sci. 2007;39(5):721-33.

28. Fabiani M, Cawthorne A, Nattabi B, Ayella EO, Ogwang M, Declich S. Investigating factors associated with uptake of HIV voluntary counselling and testing among pregnant women living in North Uganda. AIDS Care. 2007;19(6):733-9.

29. Venkatesh KK, Madiba P, De Bruyn G, Lurie MN, Coates TJ, Gray GE. Who gets tested for HIV in a South African urban township? Implications for test and treat and gender-based prevention interventions. J Acquir Immune Defic Syndr. 2011;56(2):151-65.
30. Fortson JG. The gradient in sub-Saharan Africa: socioeconomic status and HIV/AIDS. Demography. 2008;45(2):303-22.

31. Peltzer K, Matseke G, Mzolo T, Majaja M. Determinants of knowledge of HIV status in South Africa: results from a population-based HIV survey. BMC Public Health. 2009;9:174.

32. FMOH. Health and Health Related Indicators. Ethiopia: Addis Ababa; 2010

33. Yahaya LA, Jimoh AA, Balogun OR. Factors hindering acceptance of HIV/ AIDS voluntary counseling and testing (VCT) among youth in Kwara State, Nigeria. Afr J Reprod Health. 2010;14(3):159-64.

34. South A, Wringe A, Kumogola Y, Isingo R, Manyalla R, Cawley C, Zaba B, Todd J, Urassa M. Do accurate HIV and antiretroviral therapy knowledge, and previous testing experiences increase the uptake of HIV voluntary counselling and testing? Results from a cohort study in rural Tanzania. BMC Public Health. 2013;13:802.

35. Genberg BL, Kawichai S, Chingono A, Sendah M, Chariyalertsak S, Konda KA, Celentano DD. Assessing HIV/AIDS stigma and discrimination in developing countries. AIDS Behav. 2008;12(5):772-80.

36. Matovu JK, Gray RH, Makumbi F, Wawer MJ, Serwadda D, Kigozi G, Sewankambo NK, Nalugoda F. Voluntary HIV counseling and testing acceptance, sexual risk behavior and HIV incidence in Rakai, Uganda. AIDS. 2005;19(5):503-11.

37. Mitchell S, Cockcroft A, Lamothe G, Andersson N. Equity in HIV testing: evidence from a cross-sectional study in ten Southern African countries. BMC Int Health Human Rights. 2010;10:23.

38. Mulogo EM, Abdulaziz AS, Guerra R, Baine SO. Facility and home based HIV Counseling and Testing: a comparative analysis of uptake of services by rural communities in southwestern Uganda. BMC Health Serv Res. 2011;11:54.

39. Sisay S, Erku W, Medhin G, Woldeyohannes D. Perception of high school students on risk for acquiring HIV and utilization of voluntary counseling and testing (VCT) service for HIV in Debre-berhan Town, Ethiopia: a quantitative cross-sectional study. BMC Res Notes. 2014;7:518.

40. Hendriksen ES, Hlubinka D, Chariyalertsak S, Chingono A, Gray G, Mbwambo J, Mbwambo J, Richter L, Kulich M, Coates TJ. Keep talking about it: HIV/AIDS-related communication and prior HIV testing in Tanzania, Zimbabwe, South Africa, and Thailand. AIDS Behav. 2009;13(6):1213-21.

41. MacPhail C, Pettifor A, Moyo W, Rees H. Factors associated with HIV testing among sexually active South African youth aged 15-24 years. AIDS Care. 2009;21(4):456-67.

42. Laver SM. Voluntary testing and counselling for HIV. "Are adults in rural communities ready to test?" A descriptive survey. Central Afr J Med. 2001;47(4):92-7.

43. Nyblade LC, Menken J, Wawer MJ, Sewankambo NK, Serwadda D, Makumbi F, Lutalo T, Gray RH. Population-based HIV testing and counseling in rural Uganda: participation and risk characteristics. J Acquir Immune Defic Syndr. 2001;28(5):463-70.

44. Kalichman SC, Simbayi LC. HIV testing attitudes, AIDS stigma, and voluntary HIV counselling and testing in a black township in Cape Town, South Africa. Sex Transm Infect. 2003;79(6):442-7.

45. Sahlu T, Kassa E, Agonafer T, Tsegaye A, Rinke de Wit T, Gebremariam H, Doorly R, Spijkerman I, Yeneneh H, Coutinho RA, et al. Sexual behaviours, perception of risk of HIV infection, and factors associated with attending HIV post-test counselling in Ethiopia. AIDS. 1999;13(10):1263-72.

46. Aka-Dago-Akribi H, Desgrees Du Lou A, Msellati P, Dossou R, Welffens-Ekra C. Issues surrounding reproductive choice for women lying with HIV in Abidjan, Côte d'ivoire. Reprod Health Matters. 1999;7(13):20-9.

47. de Paoli MM, Manongi R, Klepp Kl. Factors influencing acceptability of voluntary counselling and HIV-testing among pregnant women in Northern Tanzania. AIDS Care. 2004;16(4):411-25.

48. Cockcroft A, Andersson N, Milne D, Mokoena T, Masisi M. Community views about routine HIV testing and antiretroviral treatment in Botswana: signs of progress from a cross sectional study. BMC Int Health Human Rights. 2007;7:5.

49. Venkatesh KK, de Bruyn G, Lurie MN, Modisenyane T, Triche EW, Gray GE, Welte A, Martinson NA. Sexual risk behaviors among HIV-infected South African men and women with their partners in a primary care program: implications for couples-based prevention. AIDS Behav. 2012;16(1):139-50.

50. Weiser SD, Heisler M, Leiter K, Percy-de Korte F, Tlou S, DeMonner S, Phaladze N, Bangsberg DR, lacopino V. Routine HIV testing in Botswana: a population-based study on attitudes, practices, and human rights concerns. PLoS Med. 2006;3(7):e261. 
51. Obermeyer CM, Neuman M, Hardon A, Desclaux A, Wanyenze R, Ky-Zerbo O, Cherutich P, Namakhoma I. Socio-economic determinants of HIV testing and counselling: a comparative study in four African countries. Tropical Med Int Health. 2013;18(9):1110-8.

52. Fylkesnes K, Sandoy IF, Jurgensen M, Chipimo PJ, Mwangala S, Michelo C. Strong effects of home-based voluntary HIV counselling and testing on acceptance and equity: a cluster randomised trial in Zambia. Soc Sci Med. 2013;86:9-16.

53. Jurgensen M, Sandoy IF, Michelo C, Fylkesnes K, Group ZS. Effects of home-based voluntary counselling and testing on HIV-related stigma: findings from a cluster-randomized trial in Zambia. Soc Sci Med. 2013;81:18-25.

Submit your next manuscript to BioMed Central and we will help you at every step:

- We accept pre-submission inquiries

- Our selector tool helps you to find the most relevant journal

- We provide round the clock customer support

- Convenient online submission

- Thorough peer review

- Inclusion in PubMed and all major indexing services

- Maximum visibility for your research

Submit your manuscript at www.biomedcentral.com/submit
Biomed Central 